\title{
Systematic review of neuromuscular diurnal activity in restless legs syndrome
}

review paper

(c) Wroclaw University of Health and Sport Sciences

DOI: https://doi.org/10.5114/hm.2023.111547

\section{MATTIAS ROMARE ${ }^{1 \oplus}$, PANAGIOTIS V. TSAKLIS ${ }^{2,3,4 \oplus}$, PARIS ALEXANDROS KRYSTALLIS ${ }^{2,4}$, GUILHERME H. ELCADI ${ }^{1,2}$ (1)}

${ }^{1}$ School of Health Sciences, Orebro University, Orebro, Sweden

${ }^{2}$ Department of Physical Education and Sport Science, ErgoMech-Lab, University of Thessaly, Trikala, Greece

${ }^{3}$ Department of Molecular Medicine and Surgery, Karolinska Institute, Solna, Sweden

${ }^{4}$ Centre of Orthopaedics and Regenerative Medicine, C.O.R.E.-C.I.R.I., Aristotle University of Thessaloniki,

Thessaloniki, Greece

\begin{abstract}
Purpose. The aim of this review was to systematically summarize the current literature on corticospinal excitation and muscle activity in restless legs syndrome (RLS) patients during daytime and diurnal activities. Three models of muscle activation in RLS directed this review: (i) evoked neuromuscular activation; (ii) sensory reflex responsiveness; (iii) voluntary muscle activation.

Methods. A literature search was conducted in PubMed and Google Scholar, and 51 articles met the primary inclusion criteria. After a quality analysis, a total 13 articles were deemed of sufficient quality for data extraction.

Results. Three studies on evoked neuromuscular activation demonstrated increased motor excitability associated with RLS. Sensory reflex responsiveness studies in RLS patients revealed increased reflex responsiveness, indicating increased spinal excitability and a possible dysfunction in afferent inhibition. Voluntary muscle activation studies showed both diurnal muscle electromyography abnormalities and an increased circadian variation in the musculature of the lower leg in RLS patients.

Conclusions. Although a number of mechanisms have been evaluated increasing the understanding of RLS, few studies have evaluated RLS during daytime and diurnal muscle activity in patients with RLS. Furthermore, potential associations with the circadian rhythm have not been thoroughly investigated, nor have methodologies been combined. Future research should aim to establish differences in muscle activity of RLS patients and associate these differences with the duration and severity of symptoms. Suggestions for further studies are provided.
\end{abstract}

Key words: restless legs syndrome, neuromuscular activity, reflex, evoked activity, electromyography

\section{Introduction}

Restless legs syndrome (RLS) was described as early as in the $17^{\text {th }}$ century by Willis (1672), and the picture of the disease as a neuropathological condition was further extended by Ekbom (1945). RLS is a commonly occurring disorder affecting up to $10 \%$ of the adult population $[1,2]$. It causes an uncontrollable urge to move the legs owing to uncomfortable sensory symptoms. This typically happens in the evening or nighttime hours, when sitting or lying down. RLS can manifest itself with both sensory and motor symptoms, such as movement disorders that make it hard to stay still (akathisia) and/or periodic limb movement, i.e., involuntary muscle contractions [3-6].

The pathological model of RLS, as suggested by Trenkwalder and Paulus [7], is multifactorial. A combination of cortical iron deficiency, dopaminergic dysfunction, and, possibly, a global disinhibition phenomenon of the cerebral cortex and spinal cord [8-13] are the potential pathophysiological mechanisms. Previous animal studies have demonstrated that inducing iron deficiency in primates caused a disruption in dopamine neurotransmission by generating a centrally

Correspondence address: Panagiotis V. Tsaklis, Department of Physical Education and Sport Science, ErgoMech-Lab, University of Thessaly, Karyes-Trikala 421 00, Greece, e-mail: tsaklis@uth.gr, https://orcid.org/0000-0002-6626-5795

Received: May 1, 2021

Accepted for publication: November 15, 2021

Citation: Romare M, Tsaklis PV, Krystallis PA, Elcadi GH. Systematic review of neuromuscular diurnal activity in restless legs syndrome. Hum Mov. 2023;24(1):21-31; doi: https://doi.org/10.5114/hm.2023.111547. 
M. Romare, P.V. Tsaklis, P.A. Krystallis, G.H. Elcadi, Neuromuscular activity in restless legs syndrome

controlled state of hypoxia, which further activates the hypoxia-induced factor (HIF) pathway. Moreover, HIF activation has been shown to increase tyrosine hydroxylase gene expression, causing an increase of cerebral dopamine concentration and activation of dopaminergic pathways [14-16]. Dopaminergic pathways have been suggested to be involved in the circadian nature of RLS symptoms, with dopamine concentration peaking during the night [17]. An increase in dopamine concentration has been reported to have opposite effects on excitatory dopamine 1 receptor (D1R) affinity and the inhibitory counterpart of dopamine 2 receptor (D2R). Increased dopamine concentration is suggested to raise the excitatory D1R activity and, conversely, to exert a desensitizing effect on the inhibitory D2R $[18,19]$. Such downregulation of the inhibitory D2R has been found in autopsies performed in RLS patients [20].

However, the conclusive pathophysiological mechanisms behind RLS are still unclear. Further contributing factors have been suggested to be brainstem disinhibition combined with impaired supraspinal dopaminergic control. The latter combination may activate spinal generator processes leading to symptoms [10-13], although other possible mechanisms have also been proposed. Tergau et al. [21] pointed at a disinhibition of the entire motor cortex in patients with idiopathic RLS.

Czesnik et al. [22] provided evidence of increased hyperexcitability of peripheral motoneurons through raised inward rectification, facilitated through hyperpolarization-activated cyclic nucleotides. Their conclusion was that the peripheral hyperexcitability of motoneurons constituted further evidence of a corticospinal pathophysiological mechanism along the descending pathways of the neuroaxis of the brain, spine, peripheral nerves, and muscles. Hence, assuming that both corticomotor and subcortical disinhibition contribute to the RLS pathophysiology, daily voluntary muscle activity may promote the hyperexcitability of the motor cortex. Consequently, it could be suggested that the diurnal corticomotor activation may affect the severity of the disorder, and further the excitability of leg muscles.

Accordingly, Paci et al. [10], with the use of electromyography (EMG), have shown a decreased EMG signal (silence periods) during gait analysis among controls compared with RLS patients. This EMG discrepancy, however, did not affect kinematics in any of the groups. Furthermore, Lin et al. [23] reported an increase in evoked reflex in comparison with controls, coupled with a decrease of sensory nerves in respect to long-latency afferent inhibition. The summation of the latter factors indicates raised motor cortical excitability of the legs and a disrupted sensorimotor integration in RLS patients. It is not clear, however, how the above pathophysiological mechanisms are influenced by the time of the day and by daily activities or how they impact on the severity of night-time symptoms. According to the International Restless Legs Syndrome Study Group, neurological and muscular features are objectively measured and evaluated as an indicator of pathologic processes in RLS and to determine therapeutical interventions. Daytime studies targeting the possible pathophysiological mechanisms of RLS may shed light into determining RLS pathophysiology and the involvement of a single cause or a combination of mechanisms. Thus, the aim of the present review is to present the current state of the literature on corticospinal excitation and muscle activity pattern in RLS patients during daytime and diurnal activities.

\section{Material and methods}

\section{Search strategy}

The initial step was to define the principal concepts for the review and our research questions. Thereafter, a dynamic search strategy was formulated. Subsequently, a literature search was performed by using the search engines of PubMed and Google Scholar. Articles were preselected to be screened by reading the titles and abstracts. Thereafter, each article was read and selected by applying a predetermined quality assessment criterion. A critical approach was used for result synthesis of the 3 overarching questions of the review. Tables of summary were created from the papers that were deemed of acceptable quality.

\section{Inclusion and exclusion criteria}

The scope of this review is limited to daytime studies with subjects diagnosed with idiopathic RLS. Animal studies were excluded, as were studies concerning periodic limb movements in non-RLS patients and other neurological pathologies that could affect spinal excitability.

Included studies with RLS patients were found relevant if they met the criteria of referring to the following issues: evoked reflex, sensory reflex, and voluntary muscle activation. Overnight sleep studies are out of the scope of this review. 


\section{Literature search}

The literature search was initially made in PubMed and Google Scholar. A summary of the search can be seen in Figure 1. Search keywords were used alone or in combination to generate results that met the criteria for the present review. Only studies in the English language and published within the previous 50 years were accepted. A total of 13 articles were deemed acceptable for data extraction and to produce tables presented in this review.

PubMed search terms that were used during this review included both Medical Subject Headings (MeSH) terms and keywords that contributed to more than 2 papers in the search. The following MeSH terms and keywords were applied, in no particular order: restless legs syndrome, muscle activity, RLS electromyography, $R L S E M G$, corticospinal excitability RLS, cortical excitability RLS, spinal excitability RLS, pathology RLS, iron deficiency $R L S$, gait analysis $R L S$, dopamine circadian rhythm RLS, circadian variation RLS, muscle activity in RLS, involuntary muscle activation RLS, Meis-1, HIF-1 dopamine, RLS reflex responsiveness, autogenic inhibition, recurrent inhibition, reciprocal inhibition.

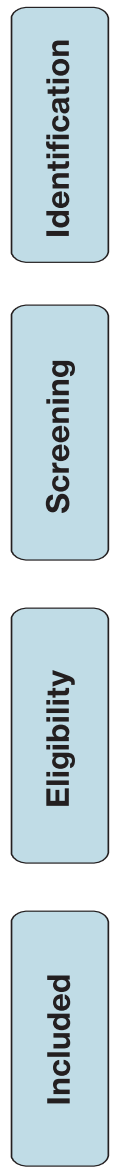

Initially, 393 articles were found in the primary PubMed and Google Scholar search. A total of 51 articles met the primary inclusion criteria as verified by scrutinizing title and abstract and were selected for a follow-up quality assessment. Of these, 11 papers were excluded when the articles were read in their entirety. Subsequently, 13 of the remaining 40 articles met the predetermined quality assessment score of $\geq 11$. The questions used for the quality assessment were derived and adapted from guidelines for research studies and checklists assessing study quality in health-related research, previously explained by Gold et al. [24]. The scoring system contained 17 items; each item could be scored as 'yes' ( 1 point), 'unknown' ( 0 ), or 'no' (0). Scores for each paper were added and the totals ranged $0-17$. On the basis of our judgment of quality, as previously suggested [24], articles scoring $\geq 65 \%$ of the maximum (i.e., at least 11 out of 17 ) were included in the present review. These articles were labelled as 'adequate quality'. Articles scoring 'no' or 'unknown' in questions 8 or 15, referring to clear RLS diagnosis and appropriate statistical analysis, were excluded from the analysis.

\section{Ethical approval}

The conducted research is not related to either human or animal use.

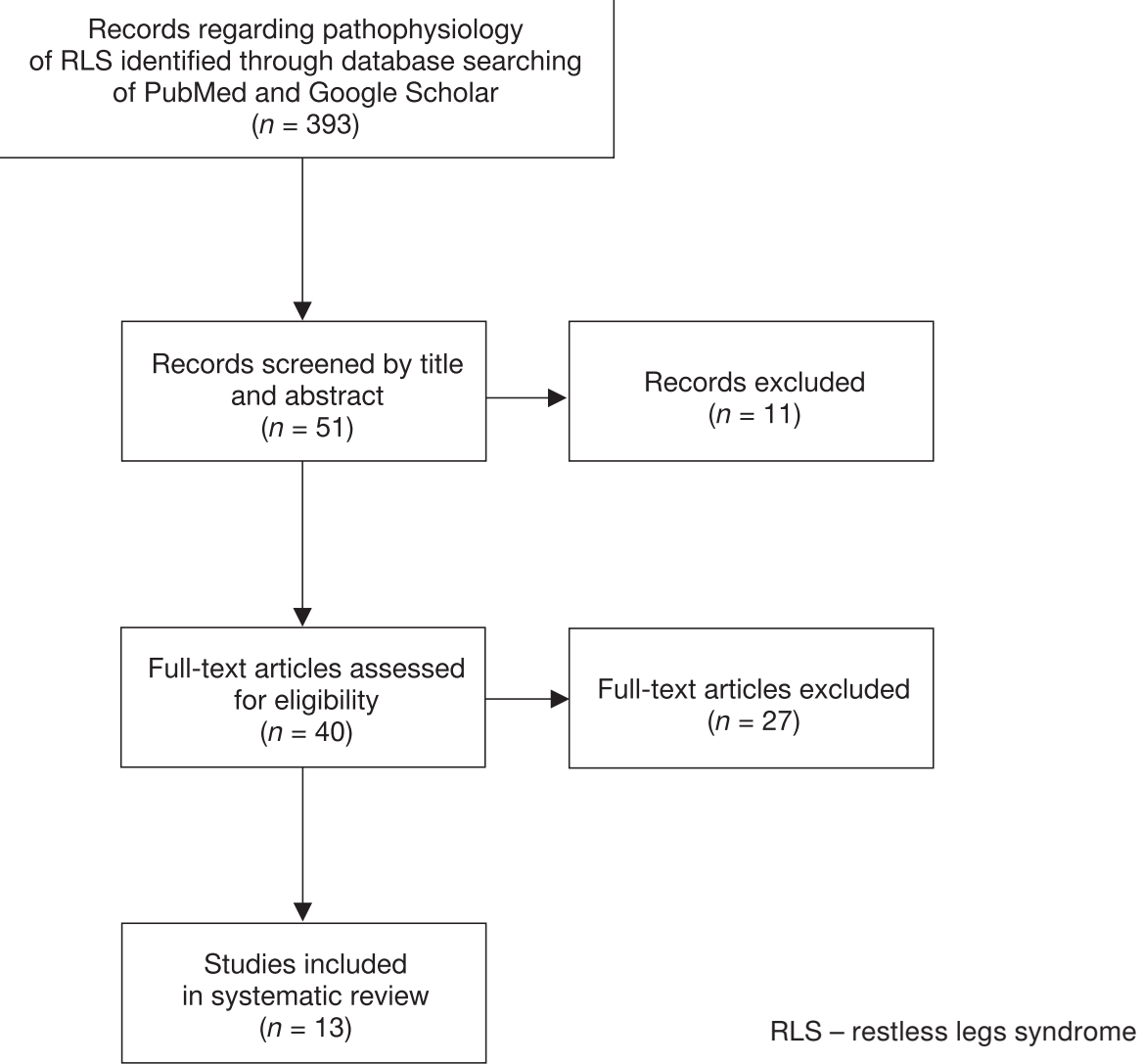

Figure 1. Flow-chart illustration of the literature search 
M. Romare, P.V. Tsaklis, P.A. Krystallis, G.H. Elcadi, Neuromuscular activity in restless legs syndrome

\section{Results}

Overall, 51 articles met the inclusion criteria as verified by reading the title and abstract. Next, 11 articles were excluded because they presented comorbidities besides RLS and also animal studies. After the primary screening process, a secondary screening process was implemented by reading the remaining 40 articles in their entirety. When a standardized quality analysis was applied, a total 13 of the remaining articles were deemed to be included in 3 separate summary tables, referring to (i) evoked neuromuscular activation studies, (ii) sensory reflex responsiveness studies, and (iii) voluntary muscle activation studies. A flowchart model of the literature search is shown in Figure 1.

\section{Evoked reflex activation studies}

Since the symptomatic characteristics of RLS are both motor and sensory in nature, the spinal cord has been suggested to be part of the pathological origin, owing to its role in both afferent sensory input and efferent motor output. Hence, a reduction in spinal inhibition might be centrally influenced by cortical hyperexcitability $[8,16,22]$.

Two electrophysiological parameters for measuring the above motor and nerve functionality are cutaneous silent periods (CSP) and the F-wave duration (FWD), evaluated by EMG. CSP represents a brief inhibitory interruption in voluntary contractions that follows an electrical stimulation of a cutaneous motor nerve. In essence, CSP plays a protective role and is regulated by spinal inhibitory pathways and superiorly partially modulated by the motor cortex. Hence, by determining the time from CSP to regained resting membrane potential, spinal excitation can be evaluated [25].

Moreover, spinal excitability has also been hitherto investigated by the EMG assessment of FWD; F-wave is produced when a supramaximal current is applied against the normal direction of nerve electrical conduction during nerve excitation [25]. Prolonged FWD is influenced by inhibitory Renshaw cells. These cells inhibit the slow-conducting motor neurons, and this inhibition is termed recurrent inhibition [26, 27]. Isak et al. [28] proposed that a decrease in the activation of inhibitory Renshaw cells might prolong FWD, with the additional activation of slow-conducting motor neurons, thereby being an indicator of decreased spinal inhibition.

Currently, there have been 4 studies that evaluated CSP and FWD in patients suffering from RLS [23,
28-30]. The results of these studies showed an increased excitability of motor neurons in RLS patients and thus a shorter CSP and altered ratio between upper body and lower body CSP [30]. Isak et al. [28] and Özsimsek and Koyuncuoglu [30] also reported a shorter CSP in patients with RLS, although the latter authors found no difference between controls and subjects in FWD. The authors suggested that CSP differences might be due to altered interneuron function or increased excitability of motor neurons influencing CSP. Two of the studies $[28,30]$ demonstrated a decreased duration of CSP, while Congiu et al. [29] revealed no difference in CSP parameters between groups. However, Congiu et al. [29] found increased FWD and concluded that it was an indicator of raised motor neuron excitability in RLS patients. Conversely, Isak et al. [28] suggested that the decrease in CSP might be due to altered spinal interneuron functioning, such as a dysfunction of inhibitory Renshaw cells. A summary of the studies is presented in Table 1.

\section{Sensory reflex responsiveness studies}

An additional model for investigating the possible hyperexcitability of the spinal cord, as a possible pathophysiological mechanism of RLS, is by assessing sensory reflex responsiveness. Reflex responsiveness can be influenced by changes in spinal excitability, hence motor responsiveness to sensory stimulation [16]. Flexor withdrawal reflex occurs when nociceptive receptors are stimulated and initiate an often-monosynaptic reflex arc with the intent of self-preservation from noxious stimulus [31]. On the other hand, crossed extension refers to a polysynaptic reflex that induces contralateral muscle activation: as one leg withdraws from a nociceptive stimulus, the contralateral leg extends in order to maintain stability [31-33]. The Hoffmann reflex (H-reflex) is a reflex response to electrical stimulation of a nerve and is similar to the patellar reflex, as it acts on the same pathway as a mechanically induced myostatic stretch reflex [34]. The main difference between the H-reflex and the stretch reflex is the absence of mechanical stimulus on the muscle spindle. It can be understood to represent an estimation of $\alpha$-motor neuron excitability when presynaptic inhibition and intrinsic excitability of the $\alpha$ -motor neurons remain constant [34].

Four studies demonstrated a circadian variation in reflex responsiveness as an indicator of spinal excitability in patients with RLS. Dafkin et al. [16, 31] investigated plantar reflex and flexor reflex/crossed extensor reflex in patients with RLS compared with 
Table 1. Summary of evoked reflex activation studies (RLS subjects compared with healthy controls)

\begin{tabular}{|c|c|c|c|c|c|}
\hline Study & $\begin{array}{c}\text { Patients }(n) \\
\text { and age (years) }\end{array}$ & $\begin{array}{l}\text { Controls }(n) \\
\text { and age (years) }\end{array}$ & Time of day & $\begin{array}{c}\text { Aspect } \\
\text { investigated }\end{array}$ & Results \\
\hline $\begin{array}{l}\text { Congiu et al., } \\
2017 \text { [29] }\end{array}$ & $\begin{array}{l}15 \text { females } \\
57.5 \pm 7.2\end{array}$ & $\begin{array}{l}17 \text { females } \\
52.5 \pm 8.7\end{array}$ & Not disclosed & FWD and CSP & $\begin{array}{l}\text { No significant differences were } \\
\text { found in either CSP parameters } \\
(p>0.05) \text { or F-wave amplitude } \\
(p>0.05) \text { between patients and } \\
\text { controls, although a significant } \\
\text { increase of FWD was detected in } \\
\text { subjects }(p=0.039 \text { and } p<0.01)\end{array}$ \\
\hline
\end{tabular}

\begin{tabular}{|c|c|c|c|c|c|}
\hline $\begin{array}{l}\text { Lin et al., } \\
2018 \text { [23] }\end{array}$ & $\begin{array}{l}14 \\
8 \text { males } \\
6 \text { females } \\
56.6 \pm 7.65\end{array}$ & $\begin{array}{l}12 \\
7 \text { males } \\
5 \text { females } \\
49.8 \pm 4.0\end{array}$ & Not disclosed & $\begin{array}{l}\text { H-reflex latency } \\
\text { and amplitude }\end{array}$ & $\begin{array}{l}\text { No significant differences were } \\
\text { found in either H-reflex latency } \\
\text { or amplitude between subjects } \\
\text { and controls }(p>0.05)\end{array}$ \\
\hline $\begin{array}{l}\text { Isak et al., } \\
2011 \text { [28] }\end{array}$ & $\begin{array}{l}24 \\
7 \text { males } \\
17 \text { females } \\
53.3 \pm 7.4\end{array}$ & $\begin{array}{l}31 \\
9 \text { males } \\
22 \text { females } \\
49.2 \pm 8.6\end{array}$ & Not disclosed & CSP and FWD & $\begin{array}{l}\text { CSP significantly shorter in } \\
\text { patients than in controls } \\
(p<0.0001) \text {, FWD significantly } \\
\text { longer in patients compared } \\
\text { with controls }(p<0.0001)\end{array}$ \\
\hline $\begin{array}{l}\text { Özsimsek and } \\
\text { Koyuncuoglu, } \\
2017 \text { [30] }\end{array}$ & $\begin{array}{l}30 \\
\text { Non-disclosed } \\
\text { age and gender } \\
\text { distribution }\end{array}$ & $\begin{array}{l}30 \\
\text { Non-disclosed } \\
\text { age and gender } \\
\text { distribution }\end{array}$ & Not disclosed & $\begin{array}{l}\text { FWL and } \\
\text { CSP/PSP }\end{array}$ & $\begin{array}{l}\text { No significant differences were } \\
\text { found in FWL between groups } \\
(p>0.05) \text {. However, PSP was } \\
\text { shorter in the tibialis anterior as } \\
\text { compared with abductor pollicis } \\
\text { brevis in subjects }(p=0.04)\end{array}$ \\
\hline
\end{tabular}

CSP - cutaneous silent period, FWD - F-wave duration, FWL - F-wave latency, PSP - peripheral silent period,

RLS - restless legs syndrome

control subjects. They showed an expected increase in reflex responsiveness when comparing day and evening in both the plantar reflex and the crossed extensor reflex in 2 separate studies, as previously did Aksu and Bara-Jimenez [35] during the symptomatic period. The results obtained by Gunduz et al. [36] are of note since they also demonstrated an increased excitability compared with controls in diurnal tests of the flexor reflex; however, they did not evaluate night-time excitability. It is important to point out that in their study, akathisia was drug-induced in the control group. In this line, other investigators [13, 37, 38] did not find any differences in the H-reflex through electrostimulation of the soleus muscle in patients with RLS and controls. Scaglione et al. [37] and Marconi et al. [38], though, reported a decrease in 1b-afferent inhibitory pathways that act on mechanoreceptors in the muscle. The latter (GTO, Golgi tendon organ) are responsible for protecting the muscle from overexertion through a mechanical feedback loop. GTO is stimulated through tension on the muscle, which sends an efferent signal towards the spinal cord. Correspondingly, an afferent inhibitory signal is directed back to the muscle, which results in a decrease in force production [39]. A sum- mary of the reviewed sensory reflex responsiveness studies is presented in Table 2 .

\section{Voluntary muscle activation studies}

There is only a handful of studies that have evaluated voluntary muscle activity in RLS patients. Interestingly, all of them have assessed voluntary muscle contraction during walking by using gait analysis and EMG [10, 40]. It may be argued, however, that since one of the primary symptoms of RLS is the uncontrollable urge to move the legs, the use of a test with predictable activation patterns may be desirable. In this line, EMG gait analysis of the working musculature may be suitable [10, 40].

Paci et al. [10] performed a gait assessment study with the use of EMG, examining the gastrocnemius lateralis (GL) and tibialis anterior (TA) muscles of RLS patients. Their results showed a subtle GL EMG abnormality (silent period) in the swing phase of the gait movement [10]. They noted that the EMG abnormality during gait in RLS patients occurred when the extension of the knee was initiated and the ankle reached a maximum degree of dorsiflexion. This is interesting, 


\section{HUMAN MOVEMENT}

M. Romare, P.V. Tsaklis, P.A. Krystallis, G.H. Elcadi, Neuromuscular activity in restless legs syndrome

Table 2. Summary of sensory reflex responsiveness studies (RLS subjects compared with healthy controls)

\begin{tabular}{|c|c|c|c|c|c|}
\hline Study & $\begin{array}{l}\text { Patients }(n) \\
\text { and age (years) }\end{array}$ & $\begin{array}{l}\text { Controls }(n) \\
\text { and age (years) }\end{array}$ & Time of day & Reflex investigated & Results \\
\hline $\begin{array}{l}\text { Aksu } \\
\text { and Bara- } \\
\text { Jimenez, } \\
2002 \text { [35] }\end{array}$ & $\begin{array}{l}20 \\
\text { Non-disclosed } \\
\text { age and gender } \\
\text { distribution }\end{array}$ & $\begin{array}{l}20 \\
\text { Non-disclosed } \\
\text { age and gender } \\
\text { distribution }\end{array}$ & $21: 30-22: 30$ & Flexor reflex & $\begin{array}{l}\text { Increased excitability in patients } \\
\text { compared with controls }(p<0.01)\end{array}$ \\
\hline \multirow[t]{2}{*}{$\begin{array}{l}\text { Dafkin } \\
\text { et al., } 2017 \\
\text { [31] }\end{array}$} & \multirow{2}{*}{$\begin{array}{l}13 \\
4 \text { males } \\
9 \text { females } \\
45.5 \pm 14.5\end{array}$} & \multirow{2}{*}{$\begin{array}{l}13 \\
4 \text { males } \\
9 \text { females } \\
42.1 \pm 14.5\end{array}$} & 06:00-08:00 & \multirow[t]{2}{*}{ Plantar reflex } & $\begin{array}{l}\text { Decreased diurnal and nocturnal } \\
\text { EMG amplitude in patients } \\
\text { compared with controls }(p<0.05)\end{array}$ \\
\hline & & & 20:00-22:00 & & $\begin{array}{l}\text { Nocturnal increase of plantar } \\
\text { reflex responsivity in patients } \\
\text { compared with controls }(p=0.04)\end{array}$ \\
\hline
\end{tabular}

\begin{tabular}{|c|c|c|c|c|c|}
\hline \multirow[t]{2}{*}{$\begin{array}{l}\text { Dafkin } \\
\text { et al., } 2018 \\
{[16]}\end{array}$} & $\begin{array}{l}12 \\
4 \text { males } \\
8 \text { females } \\
45.8 \pm 13.8\end{array}$ & $\begin{array}{l}12 \\
4 \text { males } \\
8 \text { females } \\
43.0 \pm 14.7\end{array}$ & $\begin{array}{l}06: 30-08: 00 \\
20: 00-22: 00\end{array}$ & Flexor reflex & $\begin{array}{l}\text { Nocturnal excitability increased } \\
\text { compared with diurnal in RLS } \\
\text { patients }(p=0.042) \text {. } \\
\text { No differences in controls }\end{array}$ \\
\hline & & & $\begin{array}{l}06: 30-08: 00 \\
20: 00-22: 00\end{array}$ & $\begin{array}{l}\text { Crossed extensor } \\
\text { reflex }\end{array}$ & $\begin{array}{l}\text { Nocturnal excitability increased } \\
\text { compared with diurnal in RLS } \\
\text { patients }(p=0.001) \text {. } \\
\text { No differences in controls }\end{array}$ \\
\hline
\end{tabular}

\begin{tabular}{|c|c|c|c|c|c|}
\hline $\begin{array}{l}\text { Gunduz } \\
\text { et al., } 2017 \\
{[36]}\end{array}$ & $\begin{array}{l}12 \\
\text { Non-disclosed } \\
\text { age and gender } \\
\text { distribution }\end{array}$ & $\begin{array}{l}17 \\
\text { Non-disclosed } \\
\text { age and gender } \\
\text { distribution }\end{array}$ & $13: 30-15: 30$ & Flexor reflex & $\begin{array}{l}\text { Daytime excitability increased in } \\
\text { patients compared with controls } \\
(p=0.01)\end{array}$ \\
\hline \multirow[t]{2}{*}{$\begin{array}{l}\text { Marconi } \\
\text { et al., } 2011 \\
{[38]}\end{array}$} & \multirow{2}{*}{$\begin{array}{l}9 \\
5 \text { males } \\
4 \text { females } \\
58 \pm 14\end{array}$} & \multirow{2}{*}{$\begin{array}{l}11 \\
5 \text { males } \\
6 \text { females } \\
62 \pm 7.0\end{array}$} & \multirow[t]{2}{*}{$\begin{array}{c}\text { Afternoon } \\
\text { (non-disclosed } \\
\text { time) }\end{array}$} & $\begin{array}{l}\text { Soleus H-reflex } \\
\text { through electro- } \\
\text { stimulation }\end{array}$ & No differences $(p>0.05)$ \\
\hline & & & & $\begin{array}{l}\text { Autogenic } \\
\text { inhibition (GTO) }\end{array}$ & $\begin{array}{l}\text { Decreased 1b-inhibition } \\
(p=0.007)\end{array}$ \\
\hline \multirow[t]{2}{*}{$\begin{array}{l}\text { Scaglione } \\
\text { et al., } 2008 \\
{[37]}\end{array}$} & \multirow{2}{*}{$\begin{array}{l}7 \\
\text { Non-disclosed } \\
\text { age and gender } \\
\text { distribution }\end{array}$} & \multirow{2}{*}{$\begin{array}{l}10 \\
\text { Non-disclosed } \\
\text { age and gender } \\
\text { distribution }\end{array}$} & \multirow[t]{2}{*}{$\begin{array}{l}\text { Morning (non- } \\
\text { disclosed time) }\end{array}$} & $\begin{array}{l}\text { Soleus H-reflex } \\
\text { through } \\
\text { electrostimulation }\end{array}$ & No differences $(p>0.05)$ \\
\hline & & & & $\begin{array}{l}\text { Autogenic } \\
\text { inhibition (GTO) }\end{array}$ & $\begin{array}{l}\text { Decreased 1b-inhibition } \\
(p=0.043)\end{array}$ \\
\hline $\begin{array}{l}\text { Bucher } \\
\text { et al., } 1996 \\
{[13]}\end{array}$ & $\begin{array}{l}25 \\
14 \text { males } \\
11 \text { females } \\
58.1 \pm 10.2\end{array}$ & $\begin{array}{l}15 \\
9 \text { males } \\
6 \text { females } \\
55.9 \pm 8.4\end{array}$ & $\begin{array}{l}\text { Asymptomatic } \\
\text { period }\end{array}$ & $\begin{array}{l}\text { Soleus H-reflex } \\
\text { through electro- } \\
\text { stimulation }\end{array}$ & No differences $(p>0.05)$ \\
\hline
\end{tabular}

EMG - electromyography, GTO - Golgi tendon organ, RLS - restless legs syndrome

as GL is an antagonistic muscle to the dorsiflexor TA and, as concluded by the authors, this phase of maximum dorsiflexion is usually characterized by a relative silent EMG period in GL in healthy subjects owing to reciprocal inhibition.

Dafkin et al. [40], however, addressed one limitation of the research conducted by Paci et al. [10]. They pointed out that as testing was performed in the morning - i.e., asymptomatic period - circadian variations in gait EMG activity should have been taken into consideration. Dafkin et al. [40] investigated the leg muscle activity in patients with RLS. In their study, RLS patients were compared with controls with EMG motion analysis during plantar flexion. Measurements were taken in the morning and in the evening, hence accounting for circadian variations. The authors reported differences in plantar flexion responses between RLS patients and controls and attributed their 
Table 3. Summary of voluntary muscle activation studies and resting EMG studies (RLS subjects compared with healthy controls)

\begin{tabular}{|c|c|c|c|c|c|}
\hline Study & $\begin{array}{l}\text { Patients }(n) \\
\text { and age (years) }\end{array}$ & $\begin{array}{l}\text { Controls }(n) \\
\text { and age (years) }\end{array}$ & Time of day & $\begin{array}{c}\text { Muscles } \\
\text { investigated } \\
\text { during gait }\end{array}$ & Subject response \\
\hline \multirow[t]{2}{*}{$\begin{array}{l}\text { Paci et al., } \\
2009 \text { [10] }\end{array}$} & \multirow{2}{*}{$\begin{array}{l}13 \\
3 \text { males } \\
10 \text { females } \\
57.9 \pm 13.41\end{array}$} & \multirow{2}{*}{$\begin{array}{l}8 \\
3 \text { males } \\
5 \text { females } \\
53.9 \pm 16.52\end{array}$} & \multirow[t]{2}{*}{ Morning } & $\begin{array}{l}\text { Tibialis anterior } \\
\text { Soleus }\end{array}$ & $\begin{array}{l}\text { No significant difference in patients } \\
\text { as compared with controls }(p>0.05)\end{array}$ \\
\hline & & & & $\begin{array}{l}\text { Gastrocnemius } \\
\text { lateralis } \\
\text { Gastrocnemius } \\
\text { medialis }\end{array}$ & $\begin{array}{l}\text { Significant difference, a mild EMG } \\
\text { abnormality was detected ( } p=0.003)\end{array}$ \\
\hline \multirow[t]{4}{*}{$\begin{array}{l}\text { Dafkin } \\
\text { et al., } 2018 \\
{[40]}\end{array}$} & \multirow[t]{4}{*}{$\begin{array}{l}16 \\
5 \text { males } \\
11 \text { females } \\
43.4 \pm 14.4\end{array}$} & \multirow[t]{4}{*}{$\begin{array}{l}13 \\
4 \text { males } \\
9 \text { females } \\
42.1 \pm 14.5\end{array}$} & $\begin{array}{l}19: 30-20: 30 \\
06: 30-07: 30\end{array}$ & Tibialis anterior & $\begin{array}{l}\text { No circadian variation in patients. } \\
\text { Circadian variation when compared with } \\
\text { controls, } 10 \% \text { decrease of tibialis anterior } \\
\text { activation diurnally and } 10 \% \text { increase of } \\
\text { tibialis anterior activation nocturnally } \\
(p<0.01)\end{array}$ \\
\hline & & & $\begin{array}{l}19: 30-20: 30 \\
06: 30-07: 30\end{array}$ & $\begin{array}{l}\text { Gastrocnemius } \\
\text { lateralis }\end{array}$ & $\begin{array}{l}\text { No circadian variation in patients. } \\
\text { Circadian variation when compared } \\
\text { with controls, increase in gastrocnemius } \\
\text { lateralis activity in the evening }(p<0.05)\end{array}$ \\
\hline & & & $\begin{array}{l}19: 30-20: 30 \\
06: 30-07: 30\end{array}$ & Biceps femoris & No differences $(p>0.05)$ \\
\hline & & & $\begin{array}{l}19: 30-20: 30 \\
06: 30-07: 30\end{array}$ & Rectus femoris & No differences $(p>0.05)$ \\
\hline
\end{tabular}

EMG - electromyography, RLS - restless legs syndrome

findings to circadian fluctuations in spinal excitability. In their study, RLS patients exhibited an increased EMG activity in GL and TA during the loading phase, followed by a decrease in GL activation at the terminal phase of the movement [40].

Interestingly, in line with the above, in a study by Spiegelhalder et al. [41], the correlation between resting muscle EMG and bilateral activation of the cerebellum was evaluated with functional magnetic resonance imaging (fMRI). The authors hypothesized that periodic limb movement was associated with brainstem activation and leg discomfort - measured by visual analogue scale - since the cerebellum is partially responsible for motor control [42]. In their study, the participants lay in bed in a supine position for $50 \mathrm{~min}$ utes during different hours of the day and were asked not to move voluntarily. They were monitored with surface EMG and fMRI and asked to estimate their leg discomfort on a 10-point visual analogue scale Likert scale. The authors found a negative correlation of tonic EMG and leg discomfort, as well as an association between fMRI imaging and tonic EMG, with activation in motor and somatosensory pathways. Activation was also observed in some regions of the brain that are not primarily related to motor or somatosensory functions. A summary of the studies is presented in Table 3.

\section{Discussion}

We conducted a comprehensive systematic review summarizing the current state of the literature on corticospinal excitation and muscle activity in RLS patients during daytime and diurnal activities. Our main findings were: (1) A few studies investigating evoked reflex activation demonstrated increased motor excitability associated with RLS. (2) Sensory reflex responsiveness studies in RLS patients revealed increased reflex responsiveness and a decrease in $1 \mathrm{~b}$-afferent inhibition, indicating increased spinal excitability and a possible dysfunction of both the myostatic stretch reflex and GTO. (3) Voluntary muscle activation studies reported both diurnal EMG abnormalities of GL and an increased circadian variation in the GL and TA musculature of the lower leg.

There was an association between increased corticospinal excitation and muscle activity in 2 of the studies $[10,16]$. Nonetheless, mixed consistency of 
M. Romare, P.V. Tsaklis, P.A. Krystallis, G.H. Elcadi, Neuromuscular activity in restless legs syndrome

results was observed for FWD, H-reflex, and CSP as markers of nerve conduction and interneuron function [23, 28-30]. However, we were able to identify a few common traits of overall increased reflex excitability of various nociceptive and stretch reflexes. EMG gait analysis studies demonstrated significant circadian differences in EMG activity of the GL musculature during gait, although diurnal protocols should be applied and related to night-time symptoms.

As the pathological nature of RLS is multifactorial and seemingly affects several physiological systems along the descending neuroaxis, the effort of covering the pathological origins is inherently broad. Therefore, RLS symptoms may be varied, owing to several factors that manifest simultaneously, or to one physiological system higher up in the neuroaxis affecting its descending pathway. However, an increased cortical excitability was demonstrated in patients with RLS $[11,12]$. As mentioned above, in an animal model, a deficiency in brain iron was reported to induce a central state of hypoxia, which activated the HIF pathway, increasing the tyrosine hydroxylase gene expression, thus raising dopamine in the circadian rhythm [14-16]. The increase in dopamine concentrations was shown by Barlett et al. [18] to increase the excitatory D1R and decrease the inhibitory D2R. Further influences on descending pathways can be seen in the raised excitability of peripheral motoneurons through inward rectification potassium channels, which could increase electrical excitation in the affected cells [22].

Evoked muscle activation studies presented altered FWD and CSP in RLS patients when compared with controls [28, 29]. Interestingly, Isak et al. [28] observed both a shorter CSP and longer FWD in their study, but Congiu et al. [29], with a similar protocol, found only a longer FWD. Isak et al. [28] argued that the longer FWD could result from the inhibition of small-diameter, slow-conducting motor neurons. In another study by a Turkish group [30], the authors reported no difference in FWD, but a shorter peripheral silent period in the TA muscle of RLS patients. These conflicting results may be influenced by the circadian nature of RLS, as none of the 4 papers listed the time of testing. The prolonged FWD has been explained as a consequence of Renshaw cell disinhibition, and corresponds to the results obtained by Paci et al. [10], who identified an abnormal EMG activation of GL during gait in RLS subjects. The authors suggested that this was due to a dysfunction in reciprocal inhibition, consistent with the inhibitory functioning of the Renshaw cells at the spinal level [10, 28].
Furthermore, sensory reflex responsiveness has been commonly used as a tool to estimate the descending neuroaxis component of spinal excitation. Several authors demonstrated an increase in both the plantar flexor and crossed extensor reflex responsiveness [13, 16, 31, 35-38]. Two studies followed the circadian rhythm in their protocols and found increased excitability nocturnally and decreased excitability diurnally [16, 31]. Also, Gunduz et al. [36], in an exclusively diurnal study, demonstrated increased excitability of the flexor reflex.

Scaglione et al. [37] and Marconi et al. [38] showed no difference in H-reflex responsiveness between RLS patients and controls, although a significant decrease in inhibitory $1 b$-afferent fibres was found. Inhibitory $1 \mathrm{~b}$-afferents supply the mechanoreceptor in the GTO regulating muscle activation, protecting the muscle from injury and aiding reciprocal inhibition. The summation of prolonged FWD and a decrease in 1b-afferents could indicate a dysfunction of inhibitory Renshaw cells and GTO. This may be further supported by the poor reciprocal inhibition revealed in RLS patients during gait [10].

Paci et al. [10] suggested that EMG abnormalities in RLS patients might be due to poor control of antagonistic muscle activation and that RLS patients might initiate their crossed extensor reflex during the impact phase of the contralateral leg during gait, making GL increase its activation. This was later supported by Dafkin et al. [40], who identified a significant circadian variation in the crossed extensor reflex, which increased nocturnally and decreased diurnally. Paci et al. [10] implemented the testing protocol diurnally, when RLS patients are usually asymptomatic; hence, more research is needed to elucidate EMG patterns in RLS patients during daily activities.

Spectrum effect: additional links in the literature

In addition to the conclusions made by Paci et al. [10] and Dafkin et al. [40], we suggest that EMG differences may not be exclusively limited to increased spinal reflex responsiveness and a decrease in 1b-afferent inhibitory fibres. Renshaw cells play an important role in the regulation of motor unit recruitment [43, 44]. Akazawa and Kato [43] showed that the recurrent inhibition caused by Renshaw cells had the effect of creating a linear gain between the motor output of the motor cortex and the corresponding force output. As suggested by Friedman et al. [45], Renshaw cells may reverse the order of recruitment as per the size 
principle. Such a change of order has been demonstrated in strength athletes through selective recruitment, where higher threshold motor units activate first, and lower threshold motor units are inhibited [46, 47].

Furthermore, Oskarsson et al. [48] reported a circadian variation in microcirculation in the often-affected TA musculature of the lower leg in RLS patients. The microcirculation was lower nocturnally than diurnally. In this line, Wåhlin-Larsson et al. [49] demonstrated an increase in local angiogenesis in TA of RLS patients and attributed their findings to local hypoxia. Nocturnal hypoxia may cause an increase in bilateral activation of the cerebellum, hence raising local oxygenation via higher muscle activity, as the cerebellum is partially responsible for motor output, as reported by Spiegelhalder et al. [41].

Finally, Czesnik et al. [22] concluded that the peripheral variance in hyperexcitability of motoneurons constituted evidence of the influence of a cortical component higher up in the neuroaxis hierarchy. Thus, it is not ungrounded to suggest that the increasing influence of motor cortex output, raised spinal excitability, and decreased $1 b$-afferent inhibition on the descending neuroaxis could have an impact on motor output and muscle activation. In fact, these could also affect other, uninvestigated voluntary movements, with no influence of the stretch shortening cycle seen in gait. We suggest, thus, that protocols which apply increasing force with sustained contractions should be used to evaluate muscle activation patterns in patients with RLS.

\section{Strengths and limitations}

This review makes a contribution by systematically synthesizing the literature on corticospinal excitation and muscle activity in RLS patients during daytime and diurnal activities. To our knowledge, this is the first comprehensive review of RLS and daytime muscle activation. Additionally, it is the only such review that we are aware of to address the question of muscle activation and RLS at all. However, RLS may also affect multiple mechanisms, thus yielding different consequences. We attempted to analyse the results on an RLS basis. Nevertheless, there was little consistency of study methodologies, measuring variables, and protocols. We thus suggest greater consensus on how to perform research in RLS during daytime. In this line, a better understanding of muscle activation differences between RLS patients and healthy individuals could be achieved. Furthermore, studies evaluating the consequences of daytime muscle activation for night-time symptoms are inexistent. Since patients with RLS are predominantly active during the day, it is necessary to establish if daytime effort has an impact on the onset and/ or severity of night-time symptoms.

As in all reviews, there may be incurred a publication bias; as articles featuring statistically significant results may have a higher publishing rate, this cannot be put aside as a possible weakness. Also, in several articles, the number of patients enrolled was low. Without adequate participation rates, it is not possible to appropriately assess results from a robust statistical perspective. Finally, many of the studies did not report the time of testing.

\section{Conclusions}

This review used a methodological approach and demonstrated that various mechanisms behind RLS were evaluated during daytime and diurnal muscle activation. The studies presented in this review certainly expanded the understanding of RLS. Nevertheless, how these mechanisms affect or are affected by muscle activation is still unclear and needs further investigation. Moreover, evidence is lacking on the circadian nature of symptoms.

Future research should aim to establish differences in muscle activity in RLS patients and the impact on the onset and severity of symptoms. As there is still little knowledge of the muscle activity characteristics in the RLS population, protocols with increasing muscle force or using surrogates of daily life activities could be appropriate. Finally, testing should be done with regard to duration and severity of the RLS condition. Selection criteria and response rates of all analysis groups should be detailed, and confounding factors described.

\section{Disclosure statement}

No author has any financial interest or received any financial benefit from this research.

\section{Conflict of interest}

The authors state no conflict of interest.

\section{References}

1. Allen RP, Walters AS, Montplaisir J, Hening W, Myers A, Bell TJ, et al. Restless legs syndrome prevalence and impact: REST general population study. Arch Intern Med. 2005;165(11):1286-1292; doi: 10.1001/archinte. 165.11.1286.

2. Hening W, Walters AS, Allen RP, Montplaisir J, Myers A, Ferini-Strambi L. Impact, diagnosis and treatment of restless legs syndrome (RLS) in a primary care popu- 
M. Romare, P.V. Tsaklis, P.A. Krystallis, G.H. Elcadi, Neuromuscular activity in restless legs syndrome

lation: the REST (RLS epidemiology, symptoms, and treatment) primary care study. Sleep Med. 2004;5(3): 237-246; doi: 10.1016/j.sleep.2004.03.006.

3. Walters AS. Toward a better definition of the restless legs syndrome. The International Restless Legs Syndrome Study Group. Mov Disord. 1995;10(5):634-642; doi: $10.1002 / \mathrm{mds} .870100517$.

4. Plazzi G, Vetrugno R, Meletti S, Provini F. Motor pattern of periodic limb movements in sleep in idiopathic RLS patients. Sleep Med. 2002;3(Suppl.):31-34; doi: 10.1016/S1389-9457(02)00146-6.

5. Provini F, Vetrugno R, Meletti S, Plazzi G, Solieri L, Lugaresi E, et al. Motor pattern of periodic limb movements during sleep. Neurology. 2001;57(2):300-304; doi: 10.1212/wnl.57.2.300.

6. Allen RP, Picchietti DL, Garcia-Borreguero D, Ondo WG, Walters AS, Winkelman JW, et al. Restless legs syndrome/Willis-Ekbom disease diagnostic criteria: updated International Restless Legs Syndrome Study Group (IRLSSG) consensus criteria - history, rationale, description, and significance. Sleep Med. 2014;15(8):860-873; doi: 10.1016/j.sleep.2014.03.025.

7. Trenkwalder C, Paulus W. Why do restless legs occur at rest? Pathophysiology of neuronal structures in RLS. Neurophysiology of RLS (part 2). Clin Neurophysiol. 2004;115(9):1975-1988; doi: 10.1016/j.clinph.2004.01. 031.

8. Barrière G, Cazalets JR, Bioulac B, Tison F, Ghorayeb I. The restless legs syndrome. Prog Neurobiol. 2005;77(3): 139-165; doi: 10.1016/j.pneurobio.2005.10.007.

9. Comella CL. Restless legs syndrome: treatment with dopaminergic agents. Neurology. 2002;58(4 Suppl. 1):8792; doi: 10.1212/wnl.58.suppl_1.s87.

10. Paci D, Lanuzza B, Cosentino FII, Belfiore A, Papotto M, Cocilovo A, et al. Subclinical abnormal EMG activation of the gastrocnemii during gait analysis in restless legs syndrome: a preliminary report in 13 patients. Sleep Med. 2009;10(3):312-316; doi: 10.1016/j.sleep.2008. 04.007 .

11. Lanza G, Lanuzza B, Aricò D, Cantone M, Cosentino FII, Pennisi M, et al. Direct comparison of cortical excitability to transcranial magnetic stimulation in obstructive sleep apnea syndrome and restless legs syndrome. Sleep Med. 2015;16(1):138-142; doi: 10.1016/j.sleep. 2014.08.016.

12. Lanza G, Bachmann CG, Ghorayeb I, Wang Y, Ferri R, Paulus W. Central and peripheral nervous system excitability in restless legs syndrome. Sleep Med. 2017;31: 49-60; doi: 10.1016/j.sleep.2016.05.010.

13. Bucher SF, Trenkwalder C, Oertel WH. Reflex studies and MRI in the restless legs syndrome. Acta Neurol Scand.1996;94(2):145-150;doi:10.1111/j.1600-0404. 1996.tb07045.x.

14. Unger EL, Bianco LE, Jones BC, Allen RP, Earley CJ. Low brain iron effects and reversibility on striatal dopamine dynamics. Exp Neurol. 2014;261:462-468; doi: 10.1016/j.expneurol.2014.06.023.
15. Hyacinthe C, De Deurwaerdere P, Thiollier T, Li Q, Bezard E, Ghorayeb I. Blood withdrawal affects iron store dynamics in primates with consequences on monoaminergic system function. Neuroscience. 2015;290: 621-635; doi: 10.1016/j.neuroscience.2015.01.057.

16. Dafkin C, Green A, Olivier B, McKinon W, Kerr S. Circadian variation of flexor withdrawal and crossed extensor reflexes in patients with restless legs syndrome. J Sleep Res. 2018;27(5):e12645; doi: 10.1111/jsr.12645.

17. Garcia-Borreguero D, Larrosa O, Granizo JJ, de la Llave Y, Hening WA. Circadian variation in neuroendocrine response to L-dopa in patients with restless legs syndrome. Sleep. 2004;27(4):669-673; doi: 10.1093/ sleep/27.4.669.

18. Bartlett SE, Enquist J, Hopf FW, Lee JH, Gladher F, Kharazia V, et al. Dopamine responsiveness is regulated by targeted sorting of D2 receptors. Proc Natl Acad Sci U S A. 2005;102(32):11521-11526; doi: 10.1073/pnas. 0502418102.

19. Paulus W, Trenkwalder C. Less is more: pathophysiology of dopaminergic-therapy-related augmentation in restless legs syndrome. Lancet Neurol. 2006;5(10):878-886; doi: 10.1016/S1474-4422(06)70576-2.

20. Connor JR, Wang X-S, Allen RP, Beard JL, Wiesinger JA, Felt BT, et al. Altered dopaminergic profile in the putamen and substantia nigra in restless leg syndrome. Brain. 2009;132(Pt 9):2403-2412; doi: 10.1093/brain/awp125.

21. Tergau F, Wanshura V, Canelo M, Wisher S, Wassermann EM, Ziemann U, et al. Complete suppression of voluntary motor drive during the silent period after transcranial magnetic stimulation. Exp Brain Res. 1999; 124(4):447-454; doi: 10.1007/s002210050640.

22. Czesnik D, Howells J, Bartl M, Veiz E, Ketzler R, Kemmet $\mathrm{O}$, et al. $\mathrm{I}_{\mathrm{h}}$ contributes to increased motoneuron excitability in restless legs syndrome. J Physiol. 2019; 597(2):599-609; doi: 10.1113/JP275341.

23. Lin Y, Wang Y, Zhan S, Ding Y, Hou Y, Wang L, et al. Impaired sensorimotor integration in restless legs syndrome. Front Neurol. 2018;9:568; doi: 10.3389/fneur. 2018.00568.

24. Gold JE, Hallman DM, Hellström F, Björklund M, Crenshaw AG, Djupsjobacka M, et al. Systematic review of biochemical biomarkers for neck and upper-extremity musculoskeletal disorders. Scand J Work Environ Health. 2016;42(2):103-124; doi: 10.5271/sjweh.3533.

25. Floeter MK. Cutaneous silent periods. Muscle Nerve. 2003;28(4):391-401; doi: 10.1002/mus.10447.

26. Côté M-P, Murray LM, Knikou M. Spinal control of locomotion: individual neurons, their circuits and functions. Front Physiol. 2018;9:784; doi: 10.3389/fphys. 2018.00784.

27. Toyokura M. F-wave-duration in diabetic polyneuropathy. Muscle Nerve. 1998;21(2):246-249; doi: 10.1002/ (sici)1097-4598(199802)21:2<246::aid-mus15>3.0. co;2-\#.

28. Isak B, Uluc K, Salcini C, Agan K, Tanridag T, Us O. A neurophysiological approach to the complex organi- 
sation of the spine: F-wave duration and the cutaneous silent period in restless legs syndrome. Clin Neurophysiol. 2011;122(2):383-390; doi: 10.1016/j.clinph. 2010.07.005.

29. Congiu P, Fantini ML, Milioli G, Tacconi P, Figorilli M, Gioi G, et al. F-wave duration as a specific and sensitive tool for the diagnosis of restless legs syndrome/WillisEkbom disease. J Clin Sleep Med. 2017;13(3):369-375; doi: 10.5664/jcsm.6482.

30. Özsimsek A, Koyuncuoglu HR. Electrophysiological findings of Turkish patients with restless legs syndrome. Neuropsychiatr Dis Treat. 2017;13:2005-2010; doi: 10.2147/NDT.S132903.

31. Dafkin C, Green A, Olivier B, McKinon W, Kerr S. Plantar reflex excitability is increased in the evening in restless legs syndrome patients. Neurosci Lett. 2017;660: 74-78; doi: 10.1016/j.neulet.2017.09.027.

32. Shahani BT, Young RR. Human flexor reflexes. J Neurol Neurosurg Psychiatry. 1971;34(5):616-627; doi: 10.1136/jnnp.34.5.616.

33. McArdle WD, Katch FI, Katch VL. Exercise physiology: nutrition, energy, and human performance. Philadelphia: Lippincott Williams \& Wilkins; 2015.

34. Palmieri RM, Ingersoll CD, Hoffman MA. The Hoffmann reflex: methodologic considerations and applications for use in sports medicine and athletic training research. J Athl Train. 2004;39(3):268-277.

35. Aksu M, Bara-Jimenez W. State dependent excitability changes of spinal flexor reflex in patients with restless legs syndrome secondary to chronic renal failure. Sleep Med. 2002;3(5):427-430; doi: 10.1016/s13899457(02)00073-4.

36. Gunduz A, Metin B, Metin SZ, Poyraz BC, Karadeniz D, Kiziltan G, et al. Lower limb flexor reflex: comparisons between drug-induced akathisia and restless legs syndrome. Neurosci Lett. 2017;641:40-44; doi: 10.1016/j. neulet.2017.01.042.

37. Scaglione C, Vetrugno R, Plazzi G, Rizzo G, Provini F, Montagna P, et al. Group I nonreciprocal inhibition in primary restless legs syndrome. Mov Disord. 2008;23(1): 96-100; doi: 10.1002/mds.21794.

38. Marconi B, Filippi GM, Koch G, Giacobbe V, Pecchioli C, Versace V, et al. Long-term effects on cortical excitability and motor recovery induced by repeated muscle vibration in chronic stroke patients. Neurorehabil NeuralRepair. 2011;25(1):48-60; doi: 10.1177/154596 8310376757.

39. Moore JC. The Golgi tendon organ: a review and update. Am J Occup Ther. 1984;38(4):227-236; doi: 10.5014/ ajot.38.4.227.

40. Dafkin C, Green A, Olivier B, McKinon W, Kerr S. Distal muscle activity alterations during the stance phase of gait in restless leg syndrome (RLS) patients. Sleep Med.2018;45:89-93; doi:10.1016/j.sleep.2018.01.013.

41. Spiegelhalder K, Feige B, Paul D, Riemann D, van Elst LT, Seifritz E, et al. Cerebral correlates of muscle tone fluctuations in restless legs syndrome: a pilot study with combined functional magnetic resonance imaging and anterior tibial muscle electromyography. Sleep Med. 2008;9(2):177-183; doi: 10.1016/j.sleep.2007.03.021.

42. Manto M, Bower JM, Conforto AB, Delgado-García JM, da Guarda SNF, Gerwig M, et al. Consensus paper: roles of the cerebellum in motor control - the diversity of ideas on cerebellar involvement in movement. Cerebellum. 2012;11(2):457-487; doi: 10.1007/s12311-011-0331-9.

43. Akazawa K, Kato K. Neural network model for control of muscle force based on the size principle of motor unit. ProcIEEE. 1990;78(9):1531-1535; doi: 10.1109/5.58328.

44. Uchiyama T, Akazawa K. Neural network model for muscle force control based on the size principle and recurrent inhibition of Renshaw cells. In: Malmgren H, Borga M, Niklasson L (eds.), Artificial neural networks in medicine and biology. London: Springer; 2000; 289-294.

45. Friedman WA, Sypert GW, Munson JB, Fleshman JW. Recurrent inhibition in type-identified motoneurons. J Neurophysiol. 1981;46(6):1349-1359; doi: 10.1152/ jn.1981.46.6.1349.

46. Ter Haar Romeny BM, Denier van der Gon JJ, Gielen CCAM. Changes in recruitment order of motor units in thehumanbiceps muscle.Exp Neurol.1982;78(2):360368; doi: 10.1016/0014-4886(82)90054-1.

47. Nardone A, Romanò C, Schieppati M. Selective recruitment of high-threshold human motor units during voluntary isotonic lengthening of active muscles. J Physiol. 1989;409:451-471; doi: 10.1113/jphysiol.1989.sp017507.

48. Oskarsson E, Wåhlin-Larsson B, Ulfberg J. Reduced daytime intramuscular blood flow in patients with restless legs syndrome/Willis-Ekbom disease. Psychiatry Clin Neurosci. 2014;68(8):640-643; doi: 10.1111/pcn. 12170.

49. Wåhlin-Larsson B, Ulfberg J, Aulin KP, Kadi F. The expression of vascular endothelial growth factor in skeletal muscle of patients with sleep disorders. Muscle Nerve. 2009;40(4):556-561; doi: 10.1002/mus.21357. 